\title{
President's Message: A Bright Future Ahead for BHAC
}

\section{Dear Colleagues,}

We dreamed a big dream for improving population health and wellness in our nation's universities and their surrounding communities, believed in that dream and executed it, which resulted in the first National Summit on Building Healthy Academic Communities in 2013. This Summit convened over 300 leaders from 93 University and Colleges across the United States at The Ohio State University to design cultures of wellness using a comprehensive strategy to promote optimal health and wellness in faculty, staff and students, share best practices and to envision innovative tactics that would lead to a disease-free nation. Shortly following this first Summit, the National Consortium for Building Healthy Academic Communities (BHAC) was launched with 16 founding Universities. Since the inception of this new national organization, many significant milestones have been achieved, including:

- Election of the first BHAC board,

- Launch of the BHAC web site (www.healthyacademics.org),

- Formation of an ambitious five year BHAC strategic plan,

- Successful $2^{\text {nd }}$ and $3^{\text {rd }}$ BHAC National Summits in 2015 and 2017, held at the University of California at Irvine and the University of Florida,

- Establishment of an annual national wellness competition,

- Launch of a national BHAC research/evidence-based practice grants program,

- An annual webinar series, and

- Appointment of our first editor-in-chief, Dr. Meredith Wallace Kazer, to lead our new BHAC journal.

We are indeed celebrating these landmark accomplishments, but our vision is focused on our future dreams and goals, and leapfrogging our organization to greater heights, including a home office in D.C. within 10 years. BHAC will continue to think and do the impossible in enhancing health and wellness in academic communities throughout the nation. Currently, one out of two Americans have a chronic disease and one out of four have multiple chronic conditions, yet 80 percent of these are totally preventable with healthy lifestyle behaviors. Comprehensive integrative approaches to building and sustaining a culture of wellness in academic institutions and their surrounding communities must be emphasized in order to engage people and make healthy behaviors the norm. BHAC is differentiated from other national organizations in this way with its focus on comprehensively enhancing wellbeing in faculty, staff, students and their surrounding communities. Multiple studies have supported the benefits of wellness, including people who are healthy, happy, and engaged, less absenteeism and presenteeism, and lower healthcare costs.

I have been so blessed to have the opportunity to work with the most fantastic inaugural BHAC board of directors, including Megan Amaya, Angie Brown, Colleen Harshbarger, Marcelle Holms, Cassandra Kitko, Karen Moses, and Carole Kenner. I encourage all of us to dream bigger dreams, including a disease-free world, and to persist through the challenges until our dreams come to fruition. "What will we do together in the next five to 10 years if we know we cannot fail?" Walt Disney had a dream to build Disney World when he was bankrupt, but persisted through major adversity to see its beginning construction. Word has it that, at his funeral, a reporter said to his brother "Too bad Walt never got a chance to see his dream come to fruition." His brother responded, "Quite the contrary, Walt has seen his dream for many years." That is indeed the power of a big dream, but dreams without execution do not lead to fruition. The next five to 10 years are a critical period in establishing a solid foundation for BHAC. Therefore, our fantastic BHAC organization will continue to dream big dreams together, take risks while we discover, and persist through the "character-builders" until our dreams become reality. Join us in our exciting journey to create the healthiest nation in the world.

Fond and well regards,

Bernadette Mazurek Melnyk, PhD, RN, CPNP/PMHNP, FAANP, FNAP, FAAN

Founder and President, the National Consortium for Building Healthy Academic Communities

Vice President for Health Promotion

University Chief Wellness Officer

Dean and Professor, College of Nursing

Professor of Pediatrics and Psychiatry, College of Medicine

The Ohio State University 